\title{
Late yaws
}

\section{J. L. FLUKER AND A. BOULTON HEWITT* Charing Cross Group of Hospitals, London}

The clinical course of yaws may be divided into early and late manifestations. The early stage is characterized by infective, usually moist, lesions of the skin and by lesions of other tissues, for example dactylitis, which are analogous with, but not usually identical to, the lesions which occur in secondary syphilis. The late stage of yaws, by definition those manifestations occurring more than 5 years after the initial infection, is marked by the development of hyperkeratotic skin lesions and by gummata elsewhere. This stage may be taken as being broadly comparable to the tertiary stage of syphilis, except that cardiovascular and central nervous system involvement does not occur in yaws, and there is no congenital form.

The purpose of presenting this case is to illustrate a type of lesion of the long bones which does not appear to occur in acquired syphilis and to discuss possible aetiological and immunological analogies.

\section{Case report}

A West Indian woman born on January 13, 1926, at Hanover, Jamaica, had had a reputed 'boil' on the right leg in 1935. In 1947 she was delivered in the 7th month of pregnancy and neonatal death occurred, the cause being unknown. In 1960 she attended the Orthopaedic Department of the West London Hospital with pain in the lower part of the left leg. There were no abnormal clinical findings but $x$-ray appearances were abnormal (Fig. 1) and it was decided to keep the patient under review. In 1966 she was referred to the Venereal Disease Department at the West London Hospital complaining of pain in the lower part of the right leg. Examination showed the lower third of the right tibia to be thickened and tender with some erythema of the overlying skin. The lower third of the left tibia was thickened but not unduly tender. The cardiovascular, respiratory, and central nervous systems showed no abnormality.

\section{Laboratory investigations}

Haemoglobin 95 per cent. White blood count 4,800 per cu.mm. Erythrocyte sedimentation rate $2 \mathrm{~mm} . / 1 \mathrm{st} \mathrm{hr}$ (Westergren). Cardiolipin Wassermann reaction positive. VDRL slide test positive 1 in 4 . Reiter protein complement-fixation test positive. Fluorescent treponemal antibody test positive. Treponema pallidum immobilization test positive. Serum alkaline phosphatase 7 K.A. units.

*Now at the Royal Northern Hospital, London

Received for publication February 24, 1969
Serum calcium $9 \mathrm{mg} .100 \mathrm{ml}$. Serum phosphate 3.3 mg. $/ 100 \mathrm{ml}$.

Radiographs of the legs showed hypertrophic periostitis of the lower thirds of the right and left tibiae. Subsequent films have shown little change (Figure).

\section{Diagnosis}

The probable diagnosis was periostitis of late yaws. The lesions in this disorder may be very similar to those periosteal lesions of congenital syphilis, frequently bilateral, which occur between 6 and 24 months of age (King and Catterall, 1959). They are to be distinguished from the osteoperiostitis of yaws and from the similar process which occurs after the second year of life in congenital sypilis and also in late acquired syphilis.

\section{Treatment and progress}

During 1966 the patient received two courses of intramuscular injections of procaine penicillin totalling 13.5 and 9.0 mega units respectively. Neither of these courses was followed by any marked symptomatic improvement and potassium iodide likewise failed to produce relief.

\section{Discussion}

The damage caused by the treponematoses in their various stages is largely related to the immune response of the patient and the antigenic structure of $T$. pertenue may perhaps excite an immune response closely allied to that elicited by $T$. pallidum in the immunologically immature subject with early congenital syphilis; the fact that juxta-articular nodes occur in both conditions may be a further example of this.

It could well be that the non-gummatous goundou is an analogous condition resulting from a similar pathological process.

\section{Summary}

The case is described of a 42-year-old West Indian woman who developed periostitis of the tibiae without osteitis, probably attributable to late yaws.

\section{Reference}

King, A. J., and Catterall, R. D. (1959). Brit. F. vener. Dis., 35, 116

\section{Pian tardif}

SOMMAIRE

Il est rapporté le cas d'une Antillaise de 42 ans qui a présenté une périostite des tibias sans ostéite, que l'on peut attribuer probablement à un pian tardif.

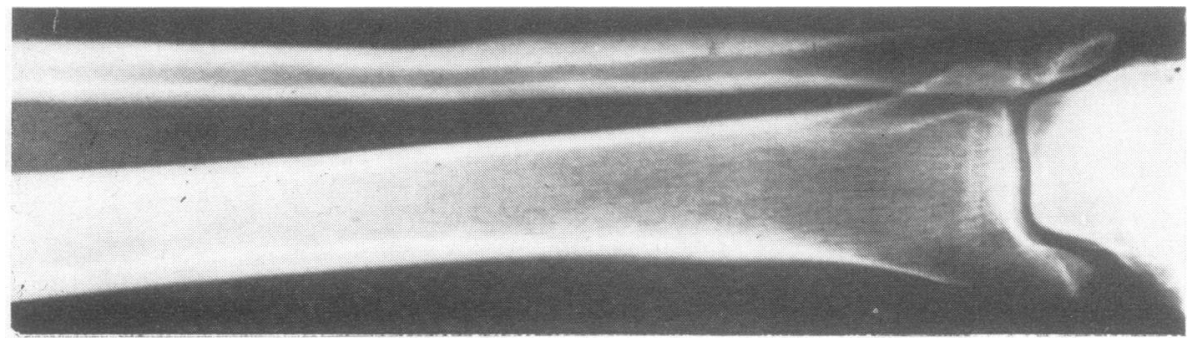

FI G URE Right leg, 1968 